\title{
IMPLEMENTASI CORPORATE SOCIAL RESPONSIBILTY THE BODY SHOP INDONESIA SEBAGAI STRATEGI PASAR
}

\author{
Dian Irma Aprianti \\ Universitas Widya Gama Mahakam Samarinda \\ me.aprianty@gmail.com \\ Novel Reonald \\ Universitas Widya Gama Mahakam Samarinda \\ Pt.nova@yahoo.co.id
}

\begin{abstract}
ABSTRAK
Tanggung jawab social harus dilakukan oleh organisasi kepada semua pihak terkait baik itu stakeholder maupun shareholder, kewajiban sosial tersebut ditujukan kepada konsumen, karyawan, pemerintah dan stakeholder. Penelitian ingin mengetahui sejauh mana peranan Corporate Social Responsibility dalam hal ini disingkat dengan CSR oleh The Body Shop Tbk dalam mengimplementasikan program teori Cause Related Marketing yang dibangun melalui anteseden marketing dan CSR dengan pemanfaat modal usaha dan kesejateraan komunitas baik ekonomi, social maupun budaya secara terus menerus.

Karya tulis didasarkan untuk membangun landasan untuk menganalisis dampak Corporate Social Responsibility The Body Shop Indonesia pada berbagai tindakan pemasaran yaitu Cause Related Marketing melalui berbagai proposisi berdasarkan anteseden dan konsekuensi dari tindakan bisnis dan sosial di masyarakat. Dampak dari kegiatan ini berkorelasi dengan tiga parameter kinerja pemasaran yaitu, ukuran ekonomi, sosial. Hasil penelitian ini menunjukkan bahwa Corporate Social Responsibility The Body Shop Indonesia telah sesuai dengan kaidah aturan Corporate Social Responsibility Perusahan di Indonesia.

Keywords : Corporate Social Responsibility, Cause Related Marketing

\section{Pendahuluan}

\subsection{Latar Belakang}

Etika bisnis dan tanggung jawab sosial di arena internasional dan masalah - masalah sosial yang dihadapi perusahaan dalam maupun luar negeri merupakan pembahasan yang semakin menarik perhatian para pemilik stakeholder.

Salah satu bentuk dari etika perusahaan adalah "CSR perusahaan atau yang lebih dikenal dengan Corporate Social Responsobility yang sudah marak sejak awal tahun 1980", perusahaan dituntut bertanggung jawab secara sosial terhadap lingkungan tempat di mana perusahaan tersebut beroperasi, tanggung jawab terhadap masyarakat setempat dan yang lebih utama adalah tanggung jawab terhadap stakeholder yang mana salah satunya adalah karyawan beserta keluarganya

The Body Shop adalah salah satu perusahaan yang mengusung tema Corporate Socal Responsibility sebagai konsentrasi perusahaan mereka dan sebagai sarana bagi pengenalan produk mereka atau strategi pasar perusahaan. Sebagai organisasi profit kosmetik terbesar kedua di dunia, The Body Shop sampai saat ini lebih diingat dengan perusahaan yang mengkampanyekan melarang uji coba bahan dan produk pada hewan (Lawan Uji Coba terhadap Hewan), memberikan dukungan pada komunitas perdagangan, kegiatan mengangkat derajat
\end{abstract}


kamu wanita, penegakkan hak asasi manusia, prokteksi planet dengan melakukan diet kantong plastik.

Corporate Social Responsibility saat ini akan cenderung berdampingan dengan konsep pemasaran, seorang konsumen saat ini tidak hanya akan membeli suatu produk, namun mereka juga akan menilai suatu produk dan perusahaan dari segi kontribusi perusahaan tersebut bagi kesejahteraan masyarakat.

Tindakan The Body Shop untuk mengusung CSR sebagai tema strategi pasar mereka tentunya atas dasar adanya regulasiyang mengatur tentang tanggung jawab sosial perusahan, di Indonesia, regulasi mengenai CSR sudah ada sejak tahun 2001. Adapun regulasi yang dibuat oleh aparat negara untuk program tanggung jawab sosial dan lingkungan adalalah sebagai berikut:.

Peraturan Pemerintah Nomor 47 Tahun 2012 tentang Tanggung Jawab Sosial dan Lingkungan Perseroan Terbatas

"Pemerintah menerbitkan PP No. 47 Tahun 2012 sebagai peraturan pelaksana dari Pasal 74 UU PT di atas. PP No. 47 Tahun 2012 yang ditandatangani oleh Presiden Susilo Bambang Yudhoyono ini hanya berisi sembilan pasal. Salah satu yang diatur adalah mekanisme pelaksanaan Tanggung Jawab Sosial dan Lingkungan perseroan."

Pasal 4 ayat (1) PP No. 47 Tahun 2012 menyebutkan, "Tanggung jawab sosial dan lingkungan dilaksanakan oleh Direksi berdasarkan rencana kerja tahunan Perseroan setelah mendapat persetujuan Dewan Komisaris atau RUPS sesuai dengan anggaran dasar Perseroan, kecuali ditentukan lain dalam peraturan perundang-undangan."

Tabel 1.1

DAFTAR KEGIATAN CSR THE BODY SHOP INDONESIA

\begin{tabular}{|l|l|l|}
\hline TAHUN & LOKASI & KEGIATAN \\
\hline 2009 & Jakarta & Memenangkan kompetisi Green Office \\
\hline 2011 & Pondok Ranji, Jakarta & $\begin{array}{l}\text { Pembangunan Gedung Sekolah untuk 26 anak pemulung di daerah Stasiun } \\
\text { Pondok Ranji }\end{array}$ \\
\hline 2013 & Jakarta & $\begin{array}{l}\text { Penggagas Against Animal Testing di Industri Kosmetik dengan } \\
\text { mengumpulkan 1.000.000 tandatangan customer untuk penghentian uji coba } \\
\text { pada hewan }\end{array}$ \\
\hline Aceh & $\begin{array}{l}\text { Pemberian donasi pada Program Kemanusiaan Aksi Cepat Tanggap (ACT) } \\
\text { sebesar Rp 155.711.187 untuk program Rekosntruksi 100 Meunasah, yaitu } \\
\text { sentra aktivitas rakyat Aceh,Korban Gempa Tsunami Aceh }\end{array}$ \\
\hline
\end{tabular}

Tabel 1.1 menjelaskan bahwa kegiatan Corporate Social Responsibility The Body Shop di Indonesia, selain itu "Manager Umum bagian Komunikasi The Body Shop Indonesia Rika Anggraini selaku GM of Corporate Affairs and Suistainability Indonesia, mengatakan bahwa online shop ternyata memberi pengaruh terhadap kinerja perusahaan pada tahun 2017". "Bisnis 
perusahaaan ternyata memberikan kinerja yang posited dan berkembang hingga dua digit. Tercatat, hingga akhir 2017, jumlah gerai The Body Shop Indonesia mencapai 142 unit. ${ }^{1}$

Berdasarkan data di atas maka peneliti bermaksud untuk menbahas bagaimana implementasi Corporate Social Resposibility The Body Shop di Indonesia sebagai strategi pasar.

\subsection{Rumusan Masalah}

Adapun masalah yang diangkat sebagai mana telah diuraikan di atas, maka perumusan masalah dalam penelitian ini adalah : Bagaimana Implementasi Corporate Social Responsibility The Body Shop Indonesia Sebagai Startegi Pasar?

\subsection{Target Luaran}

Penelitian ini ditargetkan agar dapat mengikuti Artikel Ilmiah Nasional tidak terakreditasi ber e-issn, artikel nasional terkakreditas, dan artikel ilmiah Internasional berreputasi sedangkan target tambahan diharapkan penelitian ini dapat mengikuti seminar nasional.

\subsection{Tujuaan Penelitian}

Tujuan penelitian ini adalah untuk mengetahui :

1. Bagaimana implementasi Corporate Social Responsibility The Body Shop Indonesia

2. Dengan mengetahui implementasi Corporate Social Responsibility The Body Shop, sebagai salah satu strategi pasar di Indonesia

\section{Tinjauan Pustaka}

\subsection{Penelitian Terdahulu}

Beberapa penelitian terdahulu yang telah dilakukan mengenai Corporate Social Responbibility, yakni diantaranya ;

Rika Amelia Septiana dan Emrinaldi Nur DP dengan judul "Pengaruh Corporate Social Responsibility Terhadap Profitabilitas Perusahaan" Fakultas Ekonomi Universitas Riau, 2012. “Penelitian ini menguji dampak implementasi corporate social responsibility terhadap profitabilitas perusahaan. Sampel penelitian ini menggunakan 38 perusahaan manufaktur yang listing di BEI periode tahun 20072009. Data yang digunakan adalah laporan keuangan yang dikeluarkan perusahaan tiap tahun. Teknik pengambilan sampel menggunakan metode purposive sampling. Hasil dai penelitian ini ternyata CSR berpengaruh terhadap profitabilitas perusahaan".

Hardeep Chahal da RD Sharman dalam penelitiannya Implications of Corporate Social Responsibility On Marketing Performance : A Conceptual Framework ${ }^{2}$ mengemukakan bahwa "CSR dapat berfungsi sebagai alat komunikasi pemasaran yang efektif untuk keunggulan kompetitif dan mempertahankan keunggulan bersaing tersebut dalam lingkungan yang cepat berubah dan sangat kompetitif. Meskipun ada studi penelitian yang menyediakan domain CSR dan pengaruhnya terhadap kinerja bisnis tetapi mereka memiliki berbagai sudut pandang dan tidak memadai. Mengingat konseptualisasi luas seperti itu, sangat sulit untuk mendefinisikan domain CSR.

Fokus dari penelitian ini adalah membangun landasan untuk menganalisis dampak CSR pada berbagai tindakan pemasaran melalui berbagai proposisi

\footnotetext{
${ }^{1}$ https://katadata.co.id/berita/2018/01/30/retail-loyo-the-body-shop-pacu-penjualan-online

2 Journal of Services Research, Volume 6, Number 1 (April 2006 - September 2006)@ 2006 by Institute for International Management and Technology. All Rights Reserved
} 
berdasarkan anteseden dan konsekuensi dari tindakan bisnis dan sosial. Para penulis telah menggambarkan anteseden dari CSR dari perspektif komprehensif, yang meliputi budaya organisasi, sumber daya manusia, produk dan layanan, kegiatan pembangunan sosial, dan lingkungan regulasi. Dampak dari kegiatan ini berkorelasi dengan tiga parameter kinerja pemasaran yaitu, ukuran ekonomi, sosial dan hubungan masyarkat."

\subsection{Dasar Teori}

Archie B Carroll (1999) menyatakan bahwa Corporate Social Responsibility $(C S R)$ ini adalah kegiatan tanggung jawab social sebuah perusahaan agar dapat memberi nilai tambah ( manfaat ) terhadap masyarakat. Dari sekian kegiatan pemasaran yang banyak dilakukan perusahaan dalam menerapkan CSR adalah dengan metode asas manfaat yaitu menyatukan nilai etika utama (ethical core values) ke dalam budaya organisasi perusahaan (Corporate Culture). Budaya perusahaan layaknya diterapkan jauh sebelum sebelum menggunakan menerapkan bauran promosi dengan konsep CSR yang diinginkan sebagai salah satu alat yang dapat saling menghubungkan. Dalam proses penyatuan ini nilai inti etika berfungsi sebagai perantara yang secara aktif (timbal-balik) mempengaruhi rencana strategik pemasaran bauran promosi perusahaan.

Menurut Kotler dan Lee (2005), kegiatan CSR pemasaran memiliki enam pilar, antara lain Promosi Perusahaan, pemasaran yang saling terhubung, Pemasaran sosial, Filantropi perusahaan, kelompok sukarelawan dan Praktisi social perusahaan. Perusahaan yang memilih untuk memberikan kontribusi kepada lingkungan social dan masyarakat melalui hasil penjualan ini lah yang dimaksud dengan cause related marketing, karena perusahaan lebih focus pada tujuan pendirian dan falsafah awal organisasi yaitu tindakan sosial kemasyarakatan.

\subsection{Model Konseptual}

2.4 Pernyataan Peneliti

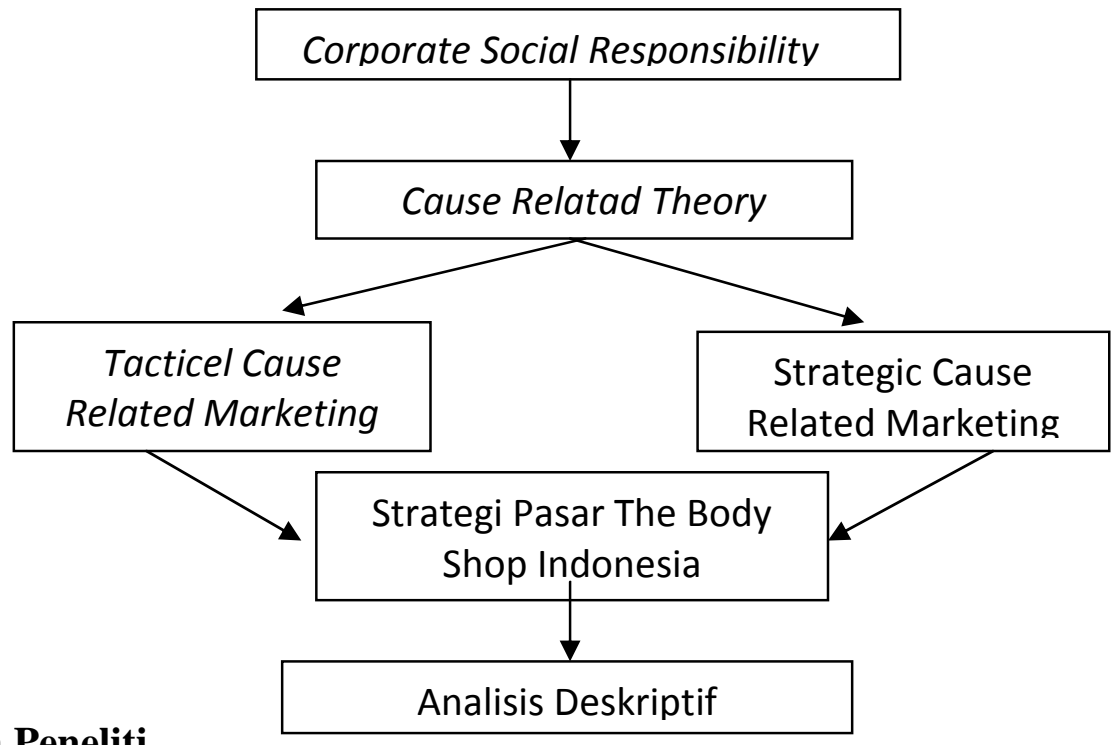

The Body Shop Indonesia telah mengimplementasikan Corporate Social Responsibility sebagai strategi pasar sesuai dengan teori Cause Related Marketing 


\section{Metode Penelitian}

\subsection{Alat Analisis}

Penelitian ini menggunakan studi deskriptif dengan pendekatan kualitatif peniltian ini merujuk pada suatu pengamatan secara terus menerus dan memerlukan waktu yang relatif lama karena membutuhkan gambaran yang detail dan akurat. Menurut Vredenbregt (1987: 38) Studi kasus ialah suatu rencana pengamtan untuk mengetahui kelengkapan suatu obyek, artiya semua fakta dikumpuklkan untuk diamati sebagai suatu unsur yang melekat, dimana tujuannya adalah mengembangkan pengetahuan yang detail mengenao suatu obyek yang diteliti yang berarti studi kasus harus diapondasikan sebagai penelitian yang mendalam dan mampu untuk dijabarkan.

2.2 Teknik Pengumpulan Data

Observasi

Obeservasi adalah salah satu cara menghimpun data yang menggunakan pengamatan indera. observasi juga dapat digunakan sebagai teknik penghimpun data yang sering digunakan dalam metode penelitian kualitatif. Observasi hakikatnya merupakan kegiatan dengan mengaplikasikan pancaindera, bisa visual, penciuman, audio, untuk memperoleh fakta yang diperlukan untuk menjawab permasalahan penelitian. Hasil observasi berupa kegiatan, kenyataan, peristiwa, objek, keadaan tertentu, dan melibatkan perasaan seseorang. Pengamatan langsung dilakukan untuk memperoleh deskripsi riil suatu kejadian untuk menjawab pertanyaan penelitian.

Bentuk dari yaitu: observasi tidak berpola ialah pengamatan yang dilakukan tidak menggunakan panduan tertentu, sehingga peneliti mengembangkan pengamatannya berdasarkan perkembangan yang terjadi di lapangan

\section{Hasil Dan Pembahasan}

\subsection{Hasil}

\section{Cause Related Marketing}

Sebagian besar pelanggan The Body Shop di Indonesia adalah wanita walaupun produk The Body Shop sendiri menyediakan produk untuk kaum pria. Dari hasil observasi peneliti diperoleh pertumbuhan outlet The Body Shop Indonesia sebagai berikut :

\section{Tabel 3.1 Jumlah Outlet The Body Shop Indonesia}

\begin{tabular}{|c|c|}
\hline TAHUN & JUMLAH OUTLET \\
\hline 2013 & 96 Outlet \\
\hline 2014 & 109 Outlet \\
\hline 2015 & 120Outlet \\
\hline 2016 & 130 Outlet \\
\hline 2017 & 142 Outlet \\
\hline 2018 & 147 Outlet \\
\hline 2019( Juni ) & 150 Outlet \\
\hline
\end{tabular}

Sumber: www.thebodyshop.co.id

Pada tahun 2016 sampai 2018 member The Body Shop telah terkumpul sebanyak 900.000 dan terus meningkat pada tahun 2019.

\section{Pembahasan}

The Body Shop Indonesia telah melakukan kegiatan Corporate Social Responsibility sejak didirikannya di Indonesia. Seperti dikatahui bahwa untuk memasarkan produknya biasanya 
akan melakukan promosi melalui berbagai media, baik media televise, cetak maupun online. Namun tidak demikian dengan The Body Shop Indonesia yang tidak pernah melakukan kegiatan promosi melalui media televise dan media cetak.

Menurut analisa penulis, apa yang telah dilakukan oleh The Body Shop Indonesia telah sesuai dengan kaidah teori Cause Related Marketing yaitu kegiatan pemasaran,suatu cara agar perusahaan dapat menguntungkan dengan melakukan kegiatan bermanfaat. Cause-related marketing adalah kegiatan khusus yakni perusahaan memberikan komitmen langsung ke konsumen untuk mendermakan sumberdaya perusahaan dari hasil penjualan barang atau jasa kepada orang-orang yang membutuhkan bantuan. Cause-related marketing memberikan tambahan ilmu yang beragam terhadap akibat dan kinerja pemasaran. Sejak berdirinya di Indonesia, The Body Shop justru focus pada kegiatan kegiatan social kemasyarakatan dimana hal tersebut tidak dilakukan oleh perusahaan lain.

Meningkatnya jumlah member dan jumlah gerai The Body Shop di Indonesia membuktikan bahwa kegiatan Cause Related Merketing The Body Shop Indonesia berjalan dengan baik. Pola kampanye yang dilakukan The Body Shop Indonesia tidak menitik beratkan pada sisi produknya saja, melainkan kampanye dalam bentuk kegiatan social kemanusiaan. Dimulai dengan mengkampanyekan No Animal Testing dimana kegiatan tersebut melibatkan para pelanggan dengan cara menandatangani pledge yang tersedia di 95 toko di seluruh Indonesia pada tahun 2011, hal tersebut justru menarik para pelanggan untuk menjadi bagian dari kampanye tersebut. Hasil tanda tangan tersebut diserahkan ke pihak Cruelty Free International dan perwakilan ASEAN.

Berikut hasil analisi deskriptif mengenai Cause Related Marketing The Body Shop Indonesi.

Tabel 3.2 : hasil empirik CSR dan CRM

\begin{tabular}{|cc|}
\hline Aktivitas & Cause-Related Marketing \\
\hline Unsur Utama & Produk, Kampanye, Sosialisasi \\
\hline Susunan Waktu & Terus Menerus \\
\hline Organisasi & Seluruh Departemen \\
\hline Tujuan & $\begin{array}{c}\text { Meningkatkan promise dan } \\
\text { penjualan produk }\end{array}$ \\
\hline $\begin{array}{c}\text { Asosiasi dan } \\
\text { Sumber daya }\end{array}$ & $\begin{array}{c}\text { Komunitas tertentu agar komunitas } \\
\text { memiliki peranan sosial }\end{array}$ \\
\hline $\begin{array}{c}\text { Hasil Kunci } \\
\text { Pikap, tindakan dan perhatian } \\
\text { konsumen terhadap isue yang } \\
\text { berkembang }\end{array}$ \\
\hline $\begin{array}{c}\text { terhadap } \\
\text { penjualan }\end{array}$ & $\begin{array}{c}\text { Berpengaruh secara langsung } \\
\text { terhadap jumlah konsuemn }\end{array}$ \\
\hline Penerimaan dana & $\begin{array}{c}\text { Dari organisasi dan kontribusi } \\
\text { penjualan }\end{array}$ \\
\hline
\end{tabular}

The Body Shop Indonesia menyadari pentingnya perusahaan untuk dapat berkontribusi dan menyalurkan kontribusi tersebut, tidak hanya untuk meningkatkan nama baik, tetapi membantu perusahaan agar maju dan berkembang. Bagi The Body Shop Indonesia CSR merupakan satu kesatuan dari sebuah kegiatan bisnis. Semakin hari semakin bertambah orang 
Indonesia memakai produk the Body Shop untuk memenuhi kebutuhan kesehatan dan kecantikan. Para konsumen mempunyai peranan membantu perusahaan untuk terus maju dan menjadi perusahaan kosmetik terkemuka. Berbagai keuntungan dari pertumbuhan dunia usaha telah menjadi bagian dari budaya perusahaan yang telah diimplementasikan dengan melibatkan masyarakat dalam kegiatan kampanye, menciptakan peluang kerja, dan memberikan benefit kepada masyarakat.

Secara tactical cause related marketing yaitu kegiatan social yang memberi manfaat namun hanya pada peroiode terentu dan dalam waktu terbatas telah dilakukan oleh The Body Shop Indonesia melalui kegiatan Green Office, melakukan renovasi terhadap tempat ibadah atau meunasah di Aceh Nangore Darusalam ketika diguncang gempa. Bantuan tersebut dilakukan pada tahun 2017.

Secara strategic cause related marketing yaitu kegiatan social yang dilakukan secara terus menerus dan dalam jangka waktu panjang, seperti yang telah dilakukan oleh The Body Shop dengan mengkampanyekan larangan menggunakan hewan sebagai bahan uji coba serta mengkampanyekan pengurangan limbah plastik.

\section{Kesimpulan dan Saran Kesimpulan}

Sesuai dengan pernyataan peneliti bahwa kegiatan Corporate Social Responsibility yang dilakukan The Body Shop Indonesia adalah bentuk dari penerapan teori Cause Related Marketing, hal tersebut terbukti dengan semakin bertambahnya outlet The Body Shop Indonesia ditengah maraknya gerai gerai kosmetik lainnya yang memutuskan untuk menutup gerai mereka di Indonesia.

Hal tersebut sesuai dengan kaidah Cause Related Marketing yaitu melakukan kegiatan positif dan baik terhadap lingkungan sesuai dengan falsafah pendirian perusahan agar perusahaan mendapatkan manfaat ekonomi dari kegiatan tersebut.

\section{Saran}

Apa yang telah dilakukan The Body Shop harus tetap dilanjutkan dan disesuaikan dengan issue - issue yang berkembang di masyarakat terutama mengenai perlindungan terhadap hewan, tumbuhan dan planet. Selain itu The Body Shop tidak boleh menghentikan kegiatan pembentukan komunitas terutama di daerah yang memerlukan bantuan baik itu dari bencana alam atau daerah termarginalkan.

\section{Buku Literatur}

\section{DAFTAR PUSTAKA}

Adkins, Sue. 2004. Cause Related Marketing: Who Cares Wins. Butterworth-Heinemann, Oxford

Basu Swastha dan Hani Handoko, Manajemen Perusahaan Analisa Perilaku Konsumen, Yogyakarta : Liberty Edisi Pertama.

Basu Swastha DH, Drs, Azas-Azas Marketing, Edisi 3

Brink, D. V. D., Pauwels, P., \& Schroder, G. O. (2006). The Effect Of Strategic And Tactical Cause-Related Marketing On Consumers' Brand Loyalty. The Journal of Consumer Marketing. Santa Barbara: 2006. Vol. 23, Iss. 1; pg. 15, 11pg

Kotler dan Keller,2012. Marketing ;An Introduction, Prentice Hall

Kuncoro Mudrajad, Metode Riset Untuk Bisnis \& Ekonomi, Erlangga,edisi 4. 2013 


\section{Jurnal Ilmiah :}

Kadek Desy Aprianthiny, Universitas Pendidikan Ghanesa Singaraja, Ilmu Pendidikan Ekonomi dengan judul " Implementasi Corporate Social Responsibility (CSR) Sebagai Modal Sosial Pada PT. Tirta Mumbul Jaya Abadi, Singaraja Bali.2015

Rika Amelia Septiana dan Emrinaldi Nur DP dengan judul " Pengaruh Corporate Social Responsibility Terhadap Profitabilitas Perusahaan" Fakultas Ekonomi Universitas Riau.2012

\section{Media Lain :}

Http://hukumonline.com

Https://ilmu-ekonomi-id.com

Https://legalklik.com

Https://thebodyshop.co.id 